\title{
UM BOMBEAMENTO HIDRÁULICO NÃO CONVENCIONAL: ELEVADOR CHEREPNOV
}

\author{
DORALICE APARECIDA FAVARO SOARES ${ }^{a}$ \\ PODALYRO AMARAL DE SOUZA
}

SOARES, D.A.F. \& SOUZA, P.A. de Um bombeamento hidráulico não convencional: elevador Cherepnov. Semina, v. 12, n. 4, p.214-223, dez. 1991.

\begin{abstract}
RESUMO
Este trabalho trata do estudo de um dispostivo alternativo para elevação de água que não necessita de combustível ou energia elétrica. O dispositivo estudado foi o elevador Cherepnov, que é de origem russa e data de 1962 . O elevador proposto pelos russos foi estudado por engenheiros americanos. Este continha controladores automáticos que necessitavam de algum tipo de energia que não fosse a disponível no escoamento. O escoamento através do elevador é descrito por uma grande quantidade de equações de considerável complexidade. Neste estudo foram feitas modificações no elevador de forma a automatizar os ciclos, utilizando somente a água e a energia disponível no escoamento. Estas modificações levaram a alterações no equacionamento do escoamento através do elevador, aumentando ainda mais o número de equações e sua complexidade, pois cada estágio foi teoricamente descrito com bastante rigor. Um total de 93 equações algébricas e diferenciais foram necessárias para descrever todo o funcionamento do ciclo de equilíbrio do elevador e para se resolver estas equações foi elaborado um programa computacional. Para ajustes e validação do modelo teórico foi construído um modelo físico nas dependências do Centro Tecnológico de Hidráulica. Apôs validado o modelo teórico, escoamentos foram simulados para se estudar vários aspectos do elevador.
\end{abstract}

PALAVRAS-CHAVE -.Elevador Cherepnov, Bombeamento não Convencional, Bombeamento Hidráulico.

\section{1 - INTRODUÇÃO}

O Elevador Cherepnov é um dispositivo para elevar água utilizando a própria energia potencial desta. Este consiste num conjunto de três tanques interligados por tubos como descrito a seguir e mostrado na figura 1.

O tanque 1 é um tanque aberto e recebe água de uma fonte de alimentação (lago, rio, rede de abastecimento de uma cidade, etc.), o tanque 2 é um tanque hermeticamente fechado e recebe do tanque 1 a água a ser elevada, o tanque 3 também é hermeticamente fechado e recebe do tanque 1 a parte da água a ser drenada.

O tanque 1 é o mais elevado, o tanque 2 está localizado ligeiramente abaixo do tanque 1 (h12) e o tanque 3 está numa posição bastante inferior ao tanque 1 (h13).

O tanque 1 é ligado ao tanque 2 através do tubo 4 e neste há uma válvula de retenção que só permite que a água passe do tanque 1 para o tanque 2. Ao tanque 2 está ligado o tubo 7 que também contém uma válvula de retenção, que não permite que a água retorne do tubo ao tanque, e é responsável pela condução da água a ser elevada.
O tanque 1 está ligado ao tanque 3 através do tubo 5 e a entrada deste se faz em uma posição bastante acima do fundo do tanque 1 (h15). Este tubo deve ser executado de forma a permitir que em determinados instantes reine a pressão atmosférica em toda a sua extensão (para que se possa garantir pressão atmosférica no interior do tanque 3 quando necessário). Ao tanque 3 está ligado um sifão \{tubo 8) responsável pela drenagem deste.

Os tanques 2 e 3 são interligados por um tubo de menor diâmetro (tubo 6) responsável pela equalização da pressão do ar nestes tanques.

O ciclo de funcionamento pode ser descrito da seguinte forma:

- o ciclo se inicia quando o nível d'água no tanque 1 sobe até a entrada do tubo $5(Z 1=h 15)$;

- neste instante o tanque 2 e o tubo 7 estão completamente cheios $\left(Z 2=Z 2_{m a ́ x}\right)$ e o tanque 3 completamente vazio;

- a pressão nos tanques 2 e 3 é igual à atmosférica;

- o sifão está completamente vazio;

- a água começa a passar ao tanque 3 através do tu- 


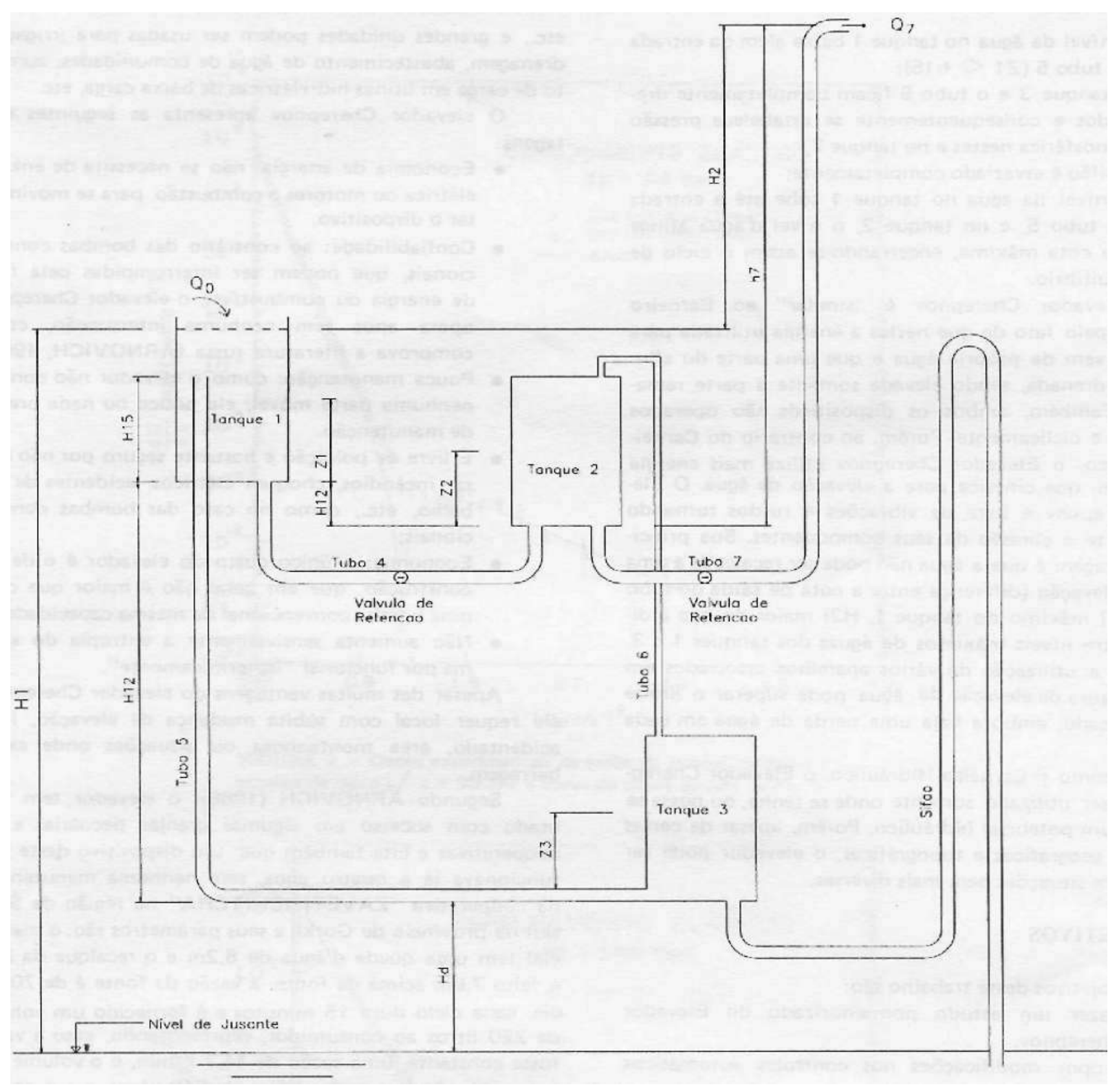

FIGURA 1 - Elevador Cherepnov

bo 5 ;

- o ar do tanque 3 começa a ser comprimido;

- a pressão interna do tanque 3 começa a subir além da atmosférica, e começa a ser transferida ao tanque 2 através do tubo 6;

- a válvula de retenção do tubo 4 (entre os tanques 1 e 2) se fecha;

- o nfvel da água no tanque 3 continua subindo até que a pressão interna dos tanques 2 e 3 fique maior que a gerada pela coluna líquida do tubo 7 $(\mathrm{p}>\mathrm{g}(\mathrm{h} 7-\mathrm{Z2})+\mathrm{po})$ e então a válvula de retenção do tubo 7 se abre e a água do tanque 2 é elevada;
- este estágio continua até que o sifão fique completamente cheio (no instante em que o sifão estiver completamente cheio, o nfvel da água nos tanques 1 e 3 será máximo e no tanque 2 será mínimo);

- com o sifão completamente cheio, começa a ser drenada a água do tanque 1 que está acima da entrada no tubo 5, e a água do tanque 3;

- o ar do tanque 2 começa a ser descomprimido;

- baixa a pressão dos tanques 2 e 3;

- a válvula de retenção do tubo 7 fecha-se, não permitindo o retorno da água ao tanque 2;

- a válvula de retenção do tubo 4 abre-se, permitindo a alimentação do tanque 2; 
- o nível da água no tanque 1 baixa além da entrada do tubo $5(\mathrm{Z1}<\mathrm{h} 15)$;

- o tanque 3 e o tubo 5 ficam completamente drenados e consequentemente se estabelece pressão atmosférica nestes e no tanque 2;

- o sifão é esvaziado completamente;

- o nível da água no tanque 1 sobe até a entrada do tubo 5, e no tanque 2, o nível d'água atinge sua cota máxima, encerrando-se assim o ciclo de equilíbrio.

O Elevador Cherepnov é "similar" ao Carneiro Hidráulico pelo fato de que nestes a energia utilizada para - recalque vem da própria água e que uma parte do afluxo total é drenada, sendo elevada somente a parte remanescente. Também, ambos os dispositivos são operados automática e ciclicamente. Porém, ao contrário do Carneiro Hidráulico, o Elevador Cherepnov utiliza mais energia potencial do que cinética para a elevação de água. 0 Elevador Cherepnov é livre de vibrações e ruídos tornando insignificante a abrasão de seus componentes. Sua principal desvantagem é que a água não pode ser recalcada a uma altura de elevação (diferença entre a cota de saída do tubo 7 e o nível máximo do tanque 1, H2) maior do que a diferença entre níveis máximos de águas dos tanques 1 e 3 , logo, com a utilização de vários aparelhos associados em série, a altura de elevação da água pode superar o limite acima indicado, embora haja uma perda de água em cada elevador.

Tal como o Carneiro Hidráulico, o Elevador Cherepnov pode ser utilizado somente onde se tenha, ou possa se produzir, um potencial hidráulico. Porém, apesar de certas limitações geográficas e topográficas, o elevador pode ser utilizado em situações bem mais diversas.

\section{OBJETIVOS}

Os objetivos deste trabalho são:

1. Fazer um estudo pormenorizado do Elevador Cherepnov.

2. Propor modificações nos controles automáticos do elevador.

3. Propor nova classificação dos estágios do ciclo de equilíbrio do elevador.

4. Elaborar um programa computacional que venha resolver as equações que descrevem o comportamento do elevador.

5. Construir um modelo físico para validação do modelo matemático, bem como obtenção de informações que não poderiam ser obtidas somente através da teoria.

\section{3 -VANTAGENS E DESVANTAGENS DO ELEVA- DOR CHEREPNOV}

O elevador Cherepnov, se largamente empregado, pode propiciar grande economia de energia, pois pequenas unidades do elevador podem ser construídas para suprimento de casas individuais, fazendas, parques, indústrias, etc, e grandes unidades podem ser usadas para irrigação, drenagem, abastecimento de água de comunidades, aumento de carga em usinas hidrelétricas de baixa carga, etc.

O elevador Cherepnov apresenta as seguintes vantagens:

- Economia de energia: não se necessita de energia elétrica ou motores a combustão para se movimentar o dispositivo.

$m$ Confiabilidade: ao contrário das bombas convencionais, que podem ser interrompidas pela falta de energia ou combustível, o elevador Cherepnov opera anos sem nenhuma interrupção, como comprova a literatura russa ÍARNOVICH, 1966).

- Pouca manutenção: como o elevador não contem nenhuma parte móvel, ele pouco ou nada precisa de manutenção.

- É livre de poluição e bastante seguro por não causar incêndios, choques elétricos, acidentes de trabalho, etc, como no caso das bombas convencionais;

" Economia: o único custo do elevador é o de sua construção, que em geral não é maior que o de uma bomba convencional da mesma capacidade;

- Não aumenta sensivelmente a entropia do sistema por funcionar "isotermicamente".

Apesar das muitas vantagens do elevador Cherepnov, ele requer local com súbita mudança de elevação, local acidentado, área montanhosa ou situações onde exista barragem.

Segundo ARNOVÍCH (1966), o elevador tem sido usado com sucesso em algumas granjas pecuárias e em cooperativas e cita também que um dispositivo deste tipo funcionava já a quatro anos, sem nenhuma manutenção, na cooperativa "ZAVETi SCHÍTCHA" na região de Spasskii na província de Gorkii e seus parâmetros são: o manancial tem uma queda d'água de $8,2 \mathrm{~m}$ e o recalque da água é feito $7,0 \mathrm{~m}$ acima da fonte, a vazão da fonte é de $70 \mathrm{~m}^{3}$ / dia, cada ciclo dura 15 minutos e é fornecido um volume de 220 litros ao consumidor, representando, caso a vazão fosse constante, uma vazão de $14,7 \mathrm{l} / \mathrm{min}$, e o volume que passa pelo dreno a cada ciclo e de 510 litros, o que corresponde a uma vazão de $36 \mathrm{l} / \mathrm{min}$.

\section{4 - TRATAMENTO TEÓRICO}

O funcionamento do elevador Cherepnov é cíclico, porém antes que ocorra o ciclo de equilíbrio, acontece um ciclo preliminar que se inicia com todos os tanques vazios (FESSEHAYE, 1982). A resolução das equações que descrevem o comportamento do elevador Cherepnov neste ciclo inicia! fornece os valores iniciais para se resolverem as equações do ciclo de equilíbrio, mas, se as condições iniciais para o ciclo de equilíbrio forem conhecidas, sem a resolução destas equações preliminares, a análise do comportamento do elevador poderá ser feita para apenas o ciclo de equilíbrio, o que fará com que o resultado seja obtido mais rapidamente (SOARES, 1992).

Semina, Ci. Exatas/Tecnol., v.12, n.4,, p.214-223, dez. 1991 
A descrição dos estágios iniciará pelo estágio 3 , pois neste estágio as condições iniciais são conhecidas (SOARES, 1992).

Cabe ressaltar que todo o equacionamento do Elevado Cherepnov - é baseado em apenas duas leis básicas e uma subsidiária:

- Leis básicas: Equação da Conservação de Massa; Equação da Conservação de Energia.

- Lei subsidiária: Lei dos gases perfeitos.

\section{1 - Descrição dos estágios}

Estágio 3

Condições iniciais:

- o nível da água no tanque 1 atinge a entrada do tubo5( Z1 =h15);

- o nível d'água no tanque 2 atinge sua cota máxima (Z2 = Z2máx);

- o tanque 3 está completamente vazio;

- a pressão no interior dos tanques 2 e 3 é igual à pressão atmosférica $(p=p o)$.

Condição final:

- a pressão no interior dos tanques 2 e 3 atinge a pressão gerada pela coluna líquida do tubo 7 $(p=p o+g(h 7-Z 2))$.

Durante este estágio a água do tanque 1 começa a passar para o tanque 3 através do tubo 5, o nível da água no tanque 3 e nos tubos 5 e 8 sobem, a pressão nos tanques 2 e 3 aumenta.

Estágio 4

Condições iniciais:

- o nível da água no tanque 2 igual ao nível máximo (Z2 = Z2máx);

- a pressão do ar nos tanques 2 e 3 é maior que a gerada pela coluna líquida do tubo 7, ou seja, $\mathrm{p}>\mathrm{po}+\mathrm{g}(\mathrm{h} 7-\mathrm{Z2})$.

Condição final:

- nível da água no tubo 5 atinge seu topo $(Z 5=$ h13 + h15).

Durante este estágio ocorre vazão através do tubo 7, Q7 > O, e portanto, baixa o nível da água no tanque 2 . Os níveis da água no tanque 3 e no tubo 8 continuam a subir. No tubo 5 o nível sobe até enchê-lo completamente.

Estágio 5

Condição inicial:

- o tubo que liga o tanque 1 ao tanque 3 (tubo 5) fica completamente cheio $(\mathrm{Z5}=\mathrm{h} 13+\mathrm{h} 15)$.

Condições finais:

- o nível da água nos tanques 1 e 3 atinge seu va- lor máximo (Z1 = Z1 máx e Z3 = Z3máx);

- a água atinge a crista do sifão formado pelo tubo $8(\mathrm{Z8I}=\mathrm{hd}+\mathrm{hp})$;

- a vazão elevada através do tubo 7 torna-se nula;

- o nívet da água no tanque 2 atinge seu valor mínimo (Z2 = Z2mín).

Durante este estádio o nível da água no tanque 2 continua a baixar, os níveis da água nos tanques 1 e 3 , e no sifão sobem e a vazão elevada (Q7) é maior que zero.

Estágio 1

Sub-estágio 1.0

Condições iniciais:

- o nível da água no sifão atinge sua crista Z8I $=h d+h p)$;

- a vazão elevada é nula $(Q 7=0)$;

- o nível da água no tanque 1 está acima da entrada do tubo 5 ( Z1 > h15);

- $\mathrm{p}>\mathrm{po}+\mathrm{g}(\mathrm{Z1}+\mathrm{h} 12-\mathrm{Z} 2)$.

Condições finais:

- o nível da água no tanque 1 baixa até a entrada do tubo 5, (Z1 = h15L ou;

- o sifão fica completamente cheio, $(Z 8 I=0)$, ou;

- $\mathrm{p}<\mathrm{po}+\mathrm{g}\{\mathrm{Z1}+\mathrm{h} 12-\mathrm{Z} 2)$.

Durante este estágio é drenada a parte da água do tanque 1 que está acima da entrada do tubo 5 e é preenchido parte ou todo o ramo descendente do sifão.

Sub-estágio 1.0.1.1

Este sub-estágio só vai ocorrer se o sub-estágio 1.0 for finalizado por ser $\mathrm{ZBI}=0$.

Condições iniciais:

- o sifão está completamente cheio $(Z 8 I=0)$;

- a vazão elevada é nula $(Q 7=0)$;

- $\mathrm{p}>\mathrm{po}+\mathrm{g}(\mathrm{Z1}+\mathrm{h} 12-\mathrm{Z2})$;

- o nível da água no tanque 1 está acima da entrada do tubo 5 (Z1 > h15).

Condições finais:

- o nível da água no tanque 1 baixa até a entrada do tubo 5 ( Z1 = h15), ou;

- $\mathrm{p}<\mathrm{po}+\mathrm{g}(\mathrm{Z1}+\mathrm{H} 12-\mathrm{Z} 2)$.

Durante este sub-estágio é drenada parte ou toda a água do tanque 1 que está acima da entrada do tubo 5.

Sub-estágio 1.0.1.2

Este sub-estágio só ocorre quando a condição de término do estágio 1.0 for Z1 $<$ h15.

Condições iniciais:

- nível da água no tanque 1 baixa até a entrada do tubo 5 (Z1 = h15); 
- a vazão elevada é nula $(Q 7=0)$;

- o ramo descendente do sifão não está completamente cheio $(Z 8 \mid>0)$.

Condições finais:

- o ramo descendente do sifão está completamente cheio $(Z 8 I=0)$, ou:

- $\mathrm{p}<\mathrm{po}+\mathrm{g}\{\mathrm{Z} 1+\mathrm{h} 12-\mathrm{Z} 2)$.

Durante este sub-estágio é enchida o ramo descendente do sifão e drenada parte da água do tubo 5 , ou, toda a água do tubo 5 e parte da água do tanque 3.

Sub-estágio 1.0 .2

Condições inciais:

- o ramo descendente do sifão está completamente cheio;

- a pressão $p$ é maior que po $+\mathrm{g}\{Z 1+\mathrm{h} 12-\mathrm{Z2})$.

Condições finais:

- a pressão $\mathrm{p}$ atinge o valor (po +g $(\mathrm{Z1}+\mathrm{h} 12-\mathrm{Z2})$;

- começa a ocorrer vazão através do tubo 4.

Durante este sub-estágio é drenada parte da água do tubo 5, ou, toda a água do tubo 5 e parte da água do tanque 3 até baixar a pressão interna dos tanques 2 e 3 e tubo 6 o suficiente para abrir a válvula de retenção do tubo 4 (que liga o tanque 1 ao tanque 2). Neste sub-estágio o nível d'água no tanque 1 fica constante.

\section{Sub-estágio 1.1}

Este sub-estágio ocorre se o sub-estágio 1.0 não ocor-

rer.

Condições iniciais:

- o nível da água no ramo ascedente do sifão atinge sua crista, $(Z 8 \mid=h d+h p)$;

- $\mathrm{p}<\mathrm{po}+\mathrm{g}(\mathrm{Z1}+\mathrm{h} 12-\mathrm{Z2})$

- o nível da água no tanque 1 atinge sua cota máxima, $\left(Z 1=Z 1_{\text {máx }}\right)$.

Condição final:

- o ramo descedente do sifão está completamente cheio.

Durante este estágio é enchido o ramo descendente do sifão, o nível da água nos tanques 1 e 3 desce e no tanque 2 sobe.

Sub-estágio 1.2 .1

Condições iniciais:

- o sifão está completamente cheio $(Z 8 \mid=0)$;

- o nível da água no tanque 1 esta acima da entrada do tubo 5, (Z1 > h15).

Condição final:

- o nível da água no tanque 1 atinge a entrada do tubo $5\{Z 1=h 15)$.

Semina, Ci. Exatas/Tecnol., v.12, n.4,p.214-223, dez. 1991
Durante este sub-estágio o nível da água nos tanques 1 e 3 baixa e no tanque 2 sobe.

Sub-estágio $\quad 1.2 .2$

Condições iniciais:

- a cota do nível da água no tanque 1 é igual à cota de entrada do tubo $5,(Z 1=h 15)$;

- o ramo descendente do sifão ainda não está completamente cheio.

- $\mathrm{p}<\mathrm{po}+\mathrm{g}(\mathrm{Z1}+\mathrm{h} 12-\mathrm{Z2})$,

Condição final:

- o sifão está completamente cheio.

Durante este estágio baixa o nfvel da água nos tanques 1 e 3 e nos tubos 5 e 8 . No tanque 2 o nfvel da água sobe, $(\mathrm{Q} 4>0$ ).

\section{Estágio 2.1}

Condição inicial:

- o nfvel da água no tanque 1 está na mesma cota da entrada do tubo $5,(Z 1=h 15)$.

Condições finais:

- o tanque 3 está completamente vazio porém o sifão está completamente cheio;

- $\mathrm{p}=\mathrm{po}$.

Durante este sub-estágio o nível da água no tanque 1 baixa além da entrada do tubo 5. A água no tanque 2 continua a subir e no tanque 3 continua a baixar até atingir sua cota mínima.

Sub-estágio 2.2

Sub-estágio 2.2 .1

Condições iniciais:

- o tanque 3 está completamente vazio;

- o sifão está completamente cheio.

Condições finais:

- o ramo ascendente do sifão está completamente vazio;

- o ramo descendente do sifão está completamente cheio.

Durante este sub-estágio é drenada a água do ramo ascendente do sifão e o nível da água no tanque 2 continua subindo.

Sub-estágio 2.2 .2

Condições iniciais:

- ramo ascedente do sifão está totalmente drenado:

- o ramo descendente do sifão está completamente cheio. 
Condição final:

- ramo descendente do sifão está completamente drenado.

Durante este sub-estágio a água continua a subir nos tanques 1 e 2 enquanto o ramo descendente do sifão é drenado. A pressão do ar nos tanques 2 e 3 e no tubo 6 continua igual à pressão atmosférica.

Ao final deste sub-estágio o nível da água no tanque 1 deveria atingir a entrada do tubo $5,(Z 1=h 15)$, e o nível da água no tanque 2 deveria atingir sua cota máxima, mas, se caso isto não acontecer, ocorrerá mais um subestágio, o sub-estágio 2.3, que será descrito à frente.

Se o nível da água atingir a entrada do tubo 5 antes do final deste sub-estágio, a água passará para o tanque 3 e será imediatamente drenada pois o sifão ainda não estará completamente vazio e drenará a água assim que ela entre no elevador, quebrando assim o seu ciclo de funcionamento. Para que isto não ocorra, deverá ser diminuída a vazão de entrada, Qo.

Se $Z 1$ baixar até zero $(Z 1=0)$, a vazão $Q 4$ fica igual à vazão de entrada Qo.

\section{Sub-estágio 2.3}

\section{Condição inicial:}

- o nível da água no tanque 1 está abaixo da entrada do tubo 5, (Z1 < h15).

Condição final:

- o nível da água no tanque 1 atinge a entrada do tubo $5(Z 1=h 15)$.

Durante este sub-estágio o nível da água no tanque 2 sobe até seu nível máximo e no tanque 1 sobe até a entrada do tubo 5 .

\section{2 - Rendimento}

O rendimento do elevador Cherepnov é dado pela relação entre as potências hidráulicas dos escoamentos na entrada do elevador e na saída do recalque, ficando representada da seguinte forma:

$$
\begin{gathered}
\eta=\frac{P_{2}}{P_{1}}-\frac{\gamma Q_{7}\left(H_{1}+H_{2}\right)}{\gamma Q_{0} H_{1}} \\
\bar{\eta}-\frac{\overline{Q_{7}}}{Q_{0}}\left(1+\frac{H_{2}}{H_{1}}\right) \\
\text { com }, \\
P_{1}-\gamma Q_{0} H_{1} \\
P_{2}=\gamma Q_{7}\left(H_{1}+H_{2}\right) \\
\overline{Q_{7}}=\frac{V_{2}^{\prime}}{T}
\end{gathered}
$$

onde:

$$
\begin{array}{ll}
\gamma & =\text { peso especifico da água, } \mathrm{Kgf} / \mathrm{m}^{3} ; \\
\mathrm{QO} & =\text { Vazão de entrada, } \mathrm{m}^{3} / \mathrm{s} ; \\
\mathrm{Q7} & =\text { Vazão elevada no instante } \mathrm{t}, \mathrm{m}^{3} / \mathrm{s} ; \\
\overline{\mathrm{Q}} & =\text { Vazäo média elevada, } \mathrm{m}^{3} / \mathrm{s} ; \\
\mathrm{H} 1 & =\text { Desnivel disponível, } \mathrm{m} ; \\
\mathrm{H} 2 & =\text { Altura efetivamente elevada, } \mathrm{m} ; \\
\mathrm{V} 2^{\prime} & =\text { Volume realmente elevado, } \mathrm{m}^{3} ; \\
\mathrm{T} & =\text { Duração do ciclo de equilíbrio, } \mathrm{s} .
\end{array}
$$

\section{S TRATAMENTO COMPUTACIONAL}

A quantidade e a complexidade das equações que descrevem o comportamento do elevador inviabilizou uma solução analítica, o que exigiu a elaboração de um programa computacional para que tal solução fosse obtida.

O objetivo do programa elaborado foi simular o escoamento através do elevador Cherepnov, e não dimensioná-lo. Com o objetivo de se ter algo bastante acessível, o programa foi elaborado em linguagem BASIC,

$O$ processo de díscretização das equações diferenciais origina equações algébricas. Parte das equações obtidas são não lineares, consequentemente, um método direto de solução destas equações não pode ser empregado, devendo ser utilizado um método iteratívo para tanto. O processo utilizado para se resolver o problema em questão foi o método de Newton-Raphson, que converge quadraticamente (CONTE, 1971). A dificuldade deste método é que ele necessita da derivada de cada uma das equações com relação a cada uma das variáveis, mas esta dificuldade foi superada facilmente por serem pequenos e bastante esparsos os sistemas de equações (SOARES, 1992).

Dos métodos testados, observou-se que o tempo de processamento requerido pelo método indireto foi muito maior que o tempo requerido pelo método direto, o que fez com que fosse escolhido o método direto para se resolver o sistema de equações linearizado.

O problema a ser resolvido é um problema de evolução, ou seja, os resultados posteriores necessitam dos resultados atuais e isto gera a necessidade de que os resultados atuais sejam realmente muito bons, pois qualquer erro repetido pode ser amplificado em cada iteração e isto produzirá uma divergência rápida do resultado real, e portanto, para se reduzir este erro foi necessária a utilização de um valor de A t (intervalo de tempo de cálculo) realmente pequeno, no caso, Dt $=0,05$ segundos.

Como o valor das variáveis envolvidas é muito diferente da unidade, o critério de precisão utilizado foi o teste do erro relativo $((\mathrm{Dxi} / \mathrm{Xi})<\mathrm{e})$.

A figura 2 mostra esquematicamente o ciclo de equilíbrio do Elevador Cherepnov. 


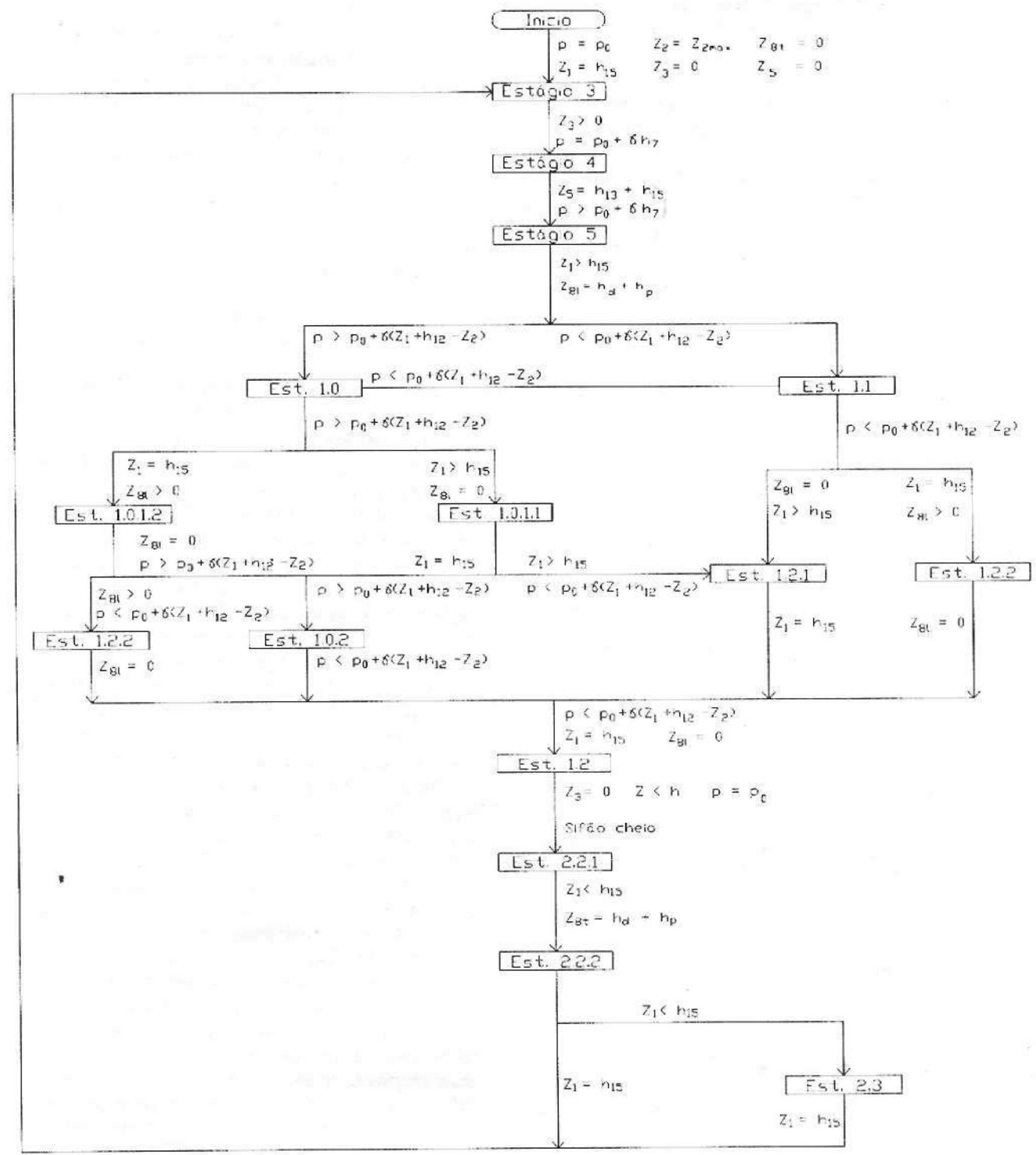

FIGURA 2 - Ciclo de equilíbrio do Elevador Cherepnov 
Os objetivos da construção de um modelo físico do elevador Cherepnov foram:

- validar o equacionamento teórico pela comparação entre resultados experimentais e resultados obtidos através da solução numérica das equações;

- verificar aspectos do comportamento do elevador que não poderiam ter sido observados apenas com o estudo teórico.

\subsection{Projeto}

Os tanques 1 e 3 foram confeccionados em acrílico transparente de espessura $7,6 \mathrm{~mm}$ e as dimensões internas são $0,317 \mathrm{~m} \times 0,333 \mathrm{~m} \times 0,60 \mathrm{~m}$. O tanque 2 foi confeccionado com o mesmo material, porém suas dimensões internas são $0,137 \mathrm{~m} \times 0,333 \mathrm{~m} \times 0,55 \mathrm{~m}$.

As tubulações que conectam os tanques são mangueiras transparentes (mangueira cristal). Tanto a parte do tubo 5 que fica dentro do tanque 1 como as curvas são de PVC rígido sotdável marrom. O diâmetro interno de cada uma das mangueiras é: $\mathrm{D} 4=\mathrm{D} 5=\mathrm{D} 7=1 \mathrm{n}$ e $\mathrm{D} 6=\mathrm{D} 8=5 / 8 \mathrm{"}$.

As válvulas de retenção foram confeccionadas utilizando um disco de cobre com espessura de $1,0 \mathrm{~mm}$, diâmetro interno igual a $17,0 \mathrm{~mm}$ e diâmetro externo igual a $51,55 \mathrm{~mm}$. Ao disco de cobre foi colado um anel de borracha flexível $(e=1,5 \mathrm{~mm})$ com uma tampa para o orifício do disco de cobre, permitindo que a água só escoasse em um único sentido.

Para se medir a vazão elevada foi construído mais um tanque em acrílico cujo volume era um pouco maior que o volume do tanque 2 .

A vazão de entrada (Qo) foi medida volumetricamente antes e depois da realização de cada ensaio.

\subsection{Ensaios}

Para a comparação entre os resultados obtidos teórica e experimentalmente, foram coletados os seguintes dados:

- cota do nível da água nos tanques 1, 2, 3 e a variação do nível da água no tanque que coletava o volume elevado, em intervalos regulares de tempo.

Os dados foram coletados da seguinte maneira:

- Em cada tanque colou-se uma fita de papel em branco em uma das paredes onde foram marcados os consecutivos níveis d'água.

Antes de se iniciar a coleta dos dados, esperou-se que pelo menos 2 ou 3 ciclos completos ocorressem para se garantir que aquele que fosse medido fosse realmente o ciclo de equilíbrio e não tivesse mais nenhuma influência do ciclo inicial.

Observou-se, durante os ensaios preliminares, que havia a formação de um vórtice na entrada do tubo 5 , que liga o tanque 1 ao tanque 3 , e este vórtice gerava um núcleo de ar em toda à extensão do tubo, permitindo que o ar compri- mido do tanque 3 escapasse, fazendo com que a pressão interna dos tanques 2 e 3 não aumentasse, ficando por um longo período igual à pressão atmosférica. Para se resolver este problema, colocou-se um quebra vórtice na entrada do tubo e como resultado obteve-se a diminuição, mas não a eliminação, do arraste de ar, porém, o ar que agora é arrastado é eliminado, antes de chegar ao tanque 3 , pelo próprio tubo 5 , não atrapalhando mais o funcionamento do elevador.

Uma vista geral do modelo físico é mostrada através da fotografia 1.

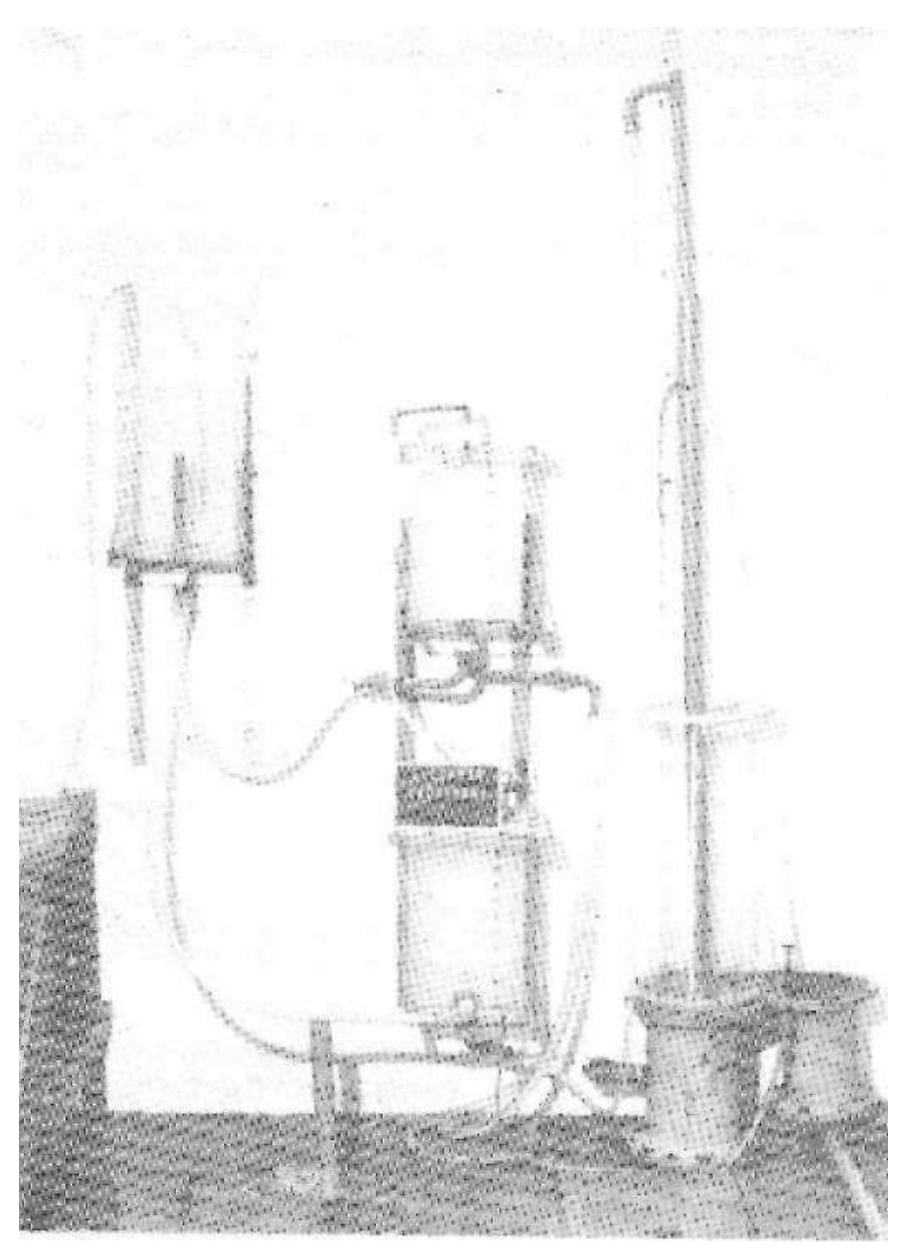

$\begin{array}{ll}\text { FOTOGRAFIA } & \begin{array}{l}\text { 1- VISTA GERAL DA INSTALAÇÃO } \\ \text { DO MODELO FÍSICO }\end{array}\end{array}$

\section{7 - ANÁLISE DOS RESULTADOS E CONCLUSÕES}

A precisão do modelo teórico foi verificada comparando-se os resultados analíticos obtidos através do programa computacional com os resultados experimentais.

A figura 3 mostra que o elevador se comporta conforme descrito teoricamente. 

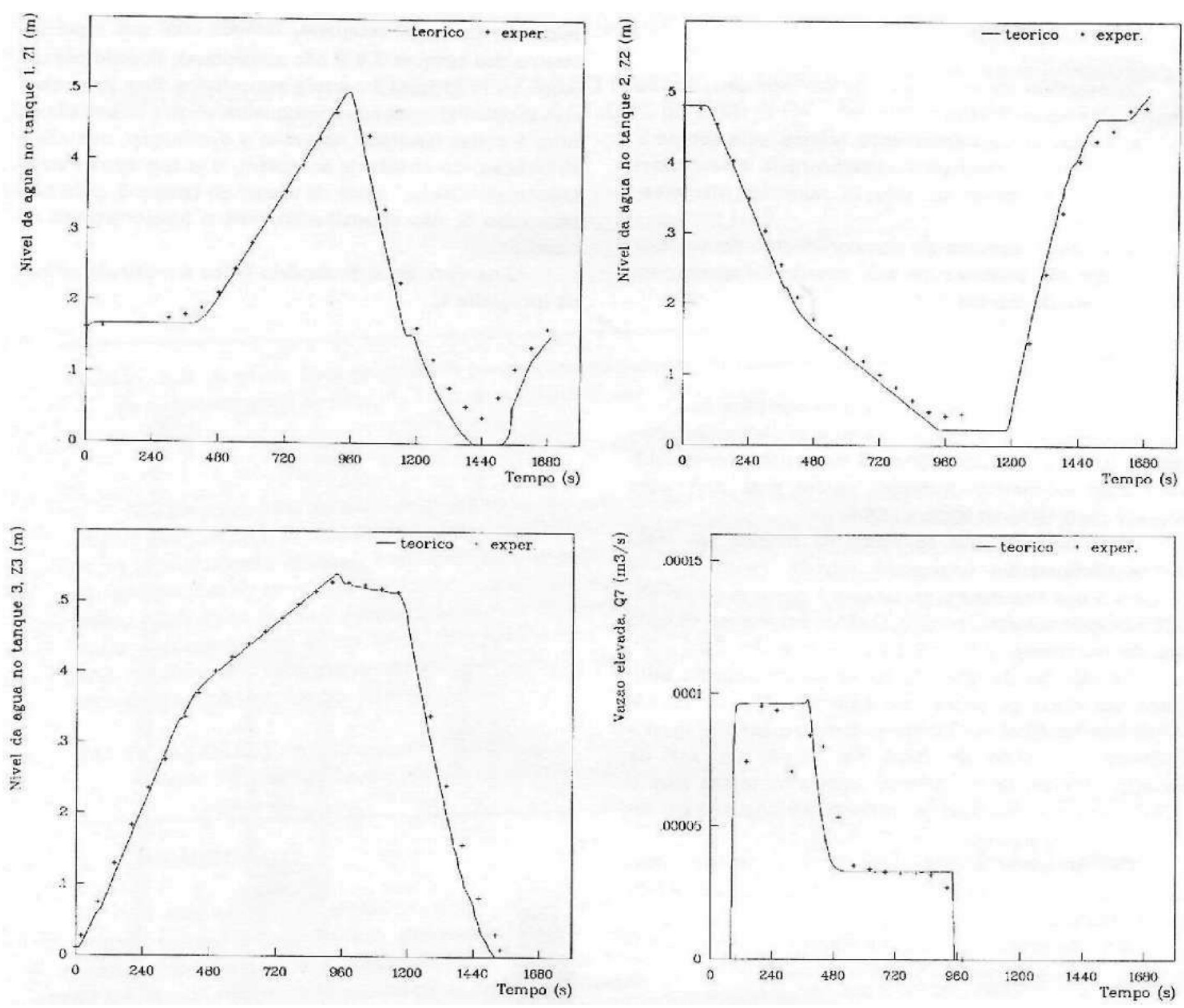

FIGURA 03 - Comparação entre os resultados obtidos através do modelo físico e do modelo teórico para $\mathrm{Cp}=2,39 \mathrm{~m} . \mathrm{H}_{1}=2,42, \mathrm{H}_{2}=0,50 \mathrm{~m} ; \mathrm{Qo}=1,022 \times 10^{4} \mathrm{~m}^{3} / \mathrm{s}$

Uma vez validado os modelos teórico e computacional, vários aspectos puderam ser analisados, como será descrito a seguir.

O elevador Cherepnov é um sistema de bombeamento bastante simples e que realmente pode ser operado sem a necessidade de nenhum tipo de energia externa ao escoamento.

Para a correta descrição do comportamento do elevador foi necessária uma nova classificação dos estágios, inclusive com a inclusão de novos sub-estágios que não constavam das propostas anteriores.

A substituição da válvula controladora do dreno do tanque 3 pelo sifão, e da ventosa pela entrada direta do tubo 5 ao tanque 3 fizeram com que o elevador funcionasse muito bem e com controladores apenas hidráulicos.
O rendimento diminui com o aumento da vazão de entrada.

O rendimento será tanto maior quanto menor for a cota da crista do sifão.

Quanto maior a altura elevada para uma dada vazão, menor é a duração do ciclo. Quanto menor a duração do ciclo maior será Q7 e portanto maior será o rendimento.

Para um dado desnível inicial, a eficiência cresce com o decréscimo da altura elevada.

O rendimento é maior quando h15 é maior.

Conforme aumenta a relação Q7/Qo aumenta a duração do ciclo.

O máximo rendimento foi observado para a relação $\mathrm{RH}=\mathrm{H} 2 / \mathrm{H} 1=0,3$.

A diminuição da cota da crista do sifão faz com que 
o volume elevado por ciclo, e a duração de cada ciclo sejam menores.

O rendimento aumenta com o aumento do volume dos tanques.

São baixas as perdas de carga que ocorrem nas tubulações por serem pequenas as velocidades.

Como na crista do sifão ocorrem pressões negativas, quando escorvado, sua cota máxima deverá ser tal que não ocorra (na crista) pressões negativas extremas.

O volume do tanque 3 necessita ser maior que o do tanque 2.

A duração do ciclo, a vazão de saída e o rendimento variam com a vazão de entrada, a cota da crista do sifão e com a distância do fundo do tanque 1 à entrada do tubo 5 , h15.

A vazão de entrada não produz efeito considerável nos valores máximos e mínimos da pressão e do volume máximo elevado.

O aumento do valor de h15 pode melhorar muito o rendimento do elevador mas, não influencia no volume elevado por ciclo. do ciclo.

O aumento de h15 faz com que haja uma redução

O aumento da área dos tanques não traz melhorias para o elevador, apenas encarecendo-o e dificultando sua instalação.

SOARES, D.A.F. \& SOUZA P.A. de A nonconventional hydraulic pumping: the Cheiepnov lifter. Semina, v. 12, n. 4, p.214-223, Dec. 1991.

\begin{abstract}
This work is about the study of an alternative device for water elevation, which does not need any kind of fitei or electric energy. The device studied was the Cherepnov water lifter, which had its origin in Rússia in 1962. The lifter proposed by the Russians was studied by American engineers. It had automatic controllers that needed some kind of energy not available in the water flow. The flow from the lifter is described by means ofa large quantity of equations of high complexity. In this study, modifications were made in the lifter to automatize the cycles using only the water and the energy available in the flow. These modifications changed the equation of the lifter's flow, this way, increasing more and more the number of equations and their complexity, since each stage was theoretically described rigorously. To describe all the cycle of the lifter equilibrium operation, a total number of 93 algebraic and differential equations were necessary. To resolve all of these equations computer program was elaborated. In order to adjuste and to validate the theoretical model a physicalmodel was built in some of the Centro Tecnológico de Hidráulica's rooms. After the validation of the theoretical model the flows were simulated to study several aspects of the lifter.
\end{abstract}

KEY WORDS: Cherepnov Lifter, Nonconventional Pumping, Hydraulic Pumping,

\title{
REFERÊNCIAS BIBLIOGRÁFICAS
}

1 - ARNOVICH, G.V., SHTAERMAN, E.Y. A teoria do elevador Cherepnov. Meklanica Zidhosti $i$ Gaza, Gorkii, v.1, n. 1, p. 176-178, jan./fev. 1966.

2 - CONTE, S.D. Elementos de análise numérica. Porto Alegre: Globo, 1971. 331 p.

3 - FESSEHAYE, Michael U. Theoretical and experimental investigation of the hydraulics of Cherepnov water lifter. Missouri: Universidade de Missouri - Columbia, 1982. Tese (Doutorado em Engenharia Civil) Universidade de Missouri - Columbi, 1982.
4 - LIU, H., FESSEHAYE, M.U., GEEKIE, R. F. The Cherepnov water lifter: theory and experiment. Journal of Hydraulic Engineering, New York, v. 111, n. 6, p. 951-969, June, 1985.

5 - SOARES, Doralice Aparecida Favaro. Um bombeamento hidrúulico näo convencional: Elevador Cherepnov. São Paulo: Escola Politécnica da Universidade de São Paulo. Dissertação (Mestrado em Engenharia Civil) - Escola Politécnica da Universidade de São Paulo, 1992. Recebido para publicação em 2/6/1992

Semina, Ci. Exatas/Tecnol., v.12, n.4, p.214-223, dez. 1991 